\title{
Gender and Interest-Based Motivation in Learning Dance
}

\author{
Bo Shen, Ang Chen, and Hope Tolley \\ University of Maryland, College Park \\ Kristin A. Scrabis \\ Teachers College, Columbia University
}

\begin{abstract}
Guided by the interest-based motivation theory, this study examined the extent to which personal interest and situational interest accounted for boys' and girls' learning outcome in a middle school physical education dance unit. Personal and situational interests, physical activity intensity, and skill/knowledge outcome were measured in a random student sample $(N=57)$. Girls demonstrated higher personal interest in dance than the boys, but both groups were equally motivated with situational interest. Although the girls were not as physically active as boys, their skill/knowledge outcome measures were higher than those of the boys. It appears that gender may have little impact on the motivational effect of situational interest and that girls' in-class learning might have higher quality than that of boys as a result of higher personal interest. The findings indicate that situational interest may motivate all students, but it is necessary to enhance personal interest in order for them to engage in quality learning.
\end{abstract}

Key words: interest, physical activity intensity, learning outcome

Motivation to learn can be defined in the pedagogical context as student willingness to engage in the content (Burke, 1995). According to Griffin (1985), gender stereotyping of physical activity affects students' willingness to learn in physical education via mediating their perception of physical ability (Williamson, 1996). Researchers (Lee, Fredenburg, Belcher, \& Cleveland, 1999) have noticed that boys and girls usually hold strong motivational and competence beliefs in physical activities they consider "gender appropriate" for themselves. In turn, the "gender appropriate" values, especially those in relation to physical activity choices, are assumed to be an underlying motivator or demotivator for boys and girls. The gendered motivator determines their responses to particular activities being taught in physical education (Hickey \& Fitzclarence, 1999).

B. Shen, A. Chen, and H. Tolley are with the Department of Kinesiology, University of Maryland, College Park, MD 20742; Kristin A. Scrabis is with the Teachers College, Columbia University, New York, NY 10027-6902. 
Gender stereotype in physical activity is socially constructed. Physical education is considered a social context in which gender stereotyped expectations are alive and well and the "gender appropriate" values sometimes are preserved in the process of learning (Hickey \& Fitzclarence, 1999). Social and cultural traditions are found to be significant forces that shape and reshape gender stereotype of physical activity (Williams \& Bedward, 2001). Boys and girls are aware of the social expectations of them in terms of participation in physical activities and sports. While boys as a group demonstrate a desire for physical contact in sports as central experiences in order to establish an acceptable masculine identity (Gard \& Meyenn, 2000), girls are struggling to negotiate their gender status that is ambiguous or contradictory to the social and cultural expectations in those sports and physical activities (Flintoff \& Scraton, 2001).

Although research on motivation and gender has provided informative findings, the focus usually is on comparing different perceived competence of boys and girls, their perceived motivation, and perceived learning (Lee, 2002). In other words, research has rarely addressed gender-related motivation issues with specific measures of learning outcomes in authentic physical education settings (Chen, 2001). In this study, we intended to examine the association between interest-based motivation and learning outcome, and differences of the association between boys and girls in middle school physical education. We chose to adopt the theoretical framework of interest-based motivation because gender stereotype in physical activities is often reflected in distinctive interest in different activities (Lee et al., 1999). In other words, interest can be a mirror in which gender impact on motivation can be directly observed and addressed.

Interest-based motivation theory suggests that interest can be a major motivation source that arises as individuals interact with the environment (Krapp, Hidi, \& Renninger, 1992). Researchers have conceptualized two kinds of interest: personal interest and situational interest. Personal interest is defined as a person's psychological disposition in preference of an action over others (Krapp et al., 1992). Situational interest, on the other hand, is defined as a momentary appealing effect of an activity on individuals in a particular context and at a particular moment (Hidi \& Anderson, 1992).

Interest researchers (Krapp et al., 1992) have found that personal interest is developed over time during a person's constant and consistent interaction with certain activities in a particular environment. It is based on increased knowledge, positive emotions, and increased value in these activities. Situational interest, on the other hand, is generated by certain stimulus characteristics in an activity (e.g., novelty) and tend to be shared among individuals (Hidi \& Anderson, 1992). Situational interest is based on a short, tentative relationship between a person and a particular activity at a given moment (Reeve, 1996). Its effect is often short-lived (Hidi, 2000). In learning, situational interest results from students' recognition of appealing features associated with a specific learning task (Mitchell, 1993) and can be manipulated by teachers to generate temporary but maximal motivation effects (Chen \& Darst, 2001).

Although there is a fundamental distinction between personal interest and situational interest, they are not dichotomous phenomena that occur in mutual isolation (Hidi, 2000). On the contrary, it has been suggested that personal interest and situational interest could interact and influence each other's development (Hidi, 2000). Situational interest, which is stimulated by environmental factors, may evoke 
or contribute to the development of long-lasting personal interest. High situational interest may enhance students' engagement in learning activities that help form student personal interest in a subject matter (Alexander, Jetton, \& Kulikowich, 1995).

Gender differences have been observed in both types of interests. Williamson (1996) implied that boys and girls might have different personal interests due to the influence of socialization and gender-role stereotyping. Clifton and Gill (1994) found that boys' and girls' personal interests in sport are usually consistent with its masculine and feminine stereotype. Most boys tend to like team sports more than girls who prefer creative and rhythm activities.

Boys and girls may perceive situational interest differently in text-based learning. Anderson, Shirey, Wilson, and Fieldings (1987) found that situational interest had stronger effects on boys' sentence recall performance than on girls', although both boys and girls performed better on recalling sentences of interest to their gender. Haussler and Hoffmann's (1998) analyses of longitudinal data of situational interest from middle school physics content revealed similar findings. Factual information from math and science appealed to $80 \%$ of male middle school students, while topics related to social relevance interested approximately $72 \%$ of female students.

In physical education, Chen and Darst (2001) reported that the boys are more likely to be attracted to tasks that have high cognitive demand than girls. But in a task with low cognitive demand, girls are more likely to be attracted than boys. Further analysis suggests, however, the gender difference in situational interest may be attributed to the inequality in physical skills between boys and girls.

Although research has revealed characteristics and motivation functions of personal interest and situational interest, the direct association between boys' and girls' interest, their motivated learning behavior, and learning outcome in physical education remains unknown. Results from previous studies on interests may not warrant a conclusion that students' learning outcome can be accounted for by their high personal and situational interest due to the lack of empirical evidence (Chen, 2001). It has become necessary to examine the effect of gender on interests and learning outcome in physical education.

Gendered preferences for activities seem to affect boys' learning behaviors more than those of girls. Boys as a group tend to become dominant in "masculine" content areas of contact sports (Clifton \& Gill, 1994; Griffin, 1985). In "feminine" content areas, such as dance, boys demonstrate minimal motivation to learn. They often regard some forms of dance, a content area in the physical education curriculum, as girls' activity (Crawford, 1994). This gendered conception prevents some forms of dance from functioning as an educational activity to benefit both boys and girls. As Hastie and Pickwell (1996) reported, the boys' gendered conception resulted in a low motivation to learn in dance classes. Some boys may develop a variety of strategies to resist learning.

Given these research findings, we assumed that square dance, a girls' activity (Crawford, 1994), was an appropriate learning context to study gender-associated motivational effects of personal and situational interests. We attempted in this study to examine the extent to which the association between interests and learning outcomes differ between middle school boys and girls in a 4-week physical education dance unit. In the investigation we focused on two specific questions: (a) how personal interest and situational interest were associated with boys' and 
girls' learning outcome in the unit, and (b) to what extent personal interest and situational interest differed between boys and girls.

We conceptualized learning outcome in physical education in the forms of physical activity intensity and skill/knowledge proficiency demonstrated in summative skill and knowledge assessments of the curriculum. It can be assumed that in an active learning environment, students should be physically active in the learning process. Therefore, physical activity intensity should be a viable process outcome demonstrated by students. Skill/knowledge assessments are considered indicative of the extent to which students have achieved the goals specified in the curriculum. The two variables represent three indicators that are often used to measure motivation: effort, persistence, and achievement (Pintrich \& Schunk, 2002). Physical intensity reflects effort and persistence a student puts into learning, whereas skill/knowledge proficiency indicates what his/her motivation results in.

The study is one of the few that attempt to explore the direct link between a motivator and measurable learning outcome. It addresses an important issue in physical education: can boys and girls be motivated to overcome socially-constructed gender stereotypes toward a physical activity while learning it? In addition, the study tested interest as a motivator that bridges the gender gap in physical education. This effort may enrich the understanding of interest-based motivation theory and help validate the efficacy of interest-based motivation theory in physical education.

\section{Methods}

\section{Participants and Setting}

This study was conducted in a middle school chosen from a pool of typical suburban middle schools in the metropolitan Washington-Baltimore area. In addition to student demographic representativeness, two criteria were used to establish the pool of schools: (a) the curriculum should be in line with both national and state standards, and (b) learning outcome should be assessed using measurable means (skill and knowledge assessment) in each unit.

Consistent with the requirement of the school district, the school's physical education curriculum was incorporated and integrated with the standards of the National Association for Sport and Physical Education (1995), where student grading was required to be based on assessment of skill and knowledge outcomes. The district's educational policies required that physical education must be taught by teachers certified in physical education and that elementary and middle schools do not offer interscholastic athletic programs to the students. The primary responsibility of physical education teachers, therefore, was to teach physical education full time in their schools.

There were approximately 600 students from 6th grade to 8th grade in the school. The majority of students in this school came from middle-class families and $84.9 \%$ were Caucasian, 7\% African Americans, and 7.2\% Asian Americans. The poverty level of the student body, as measured by the number of students receiving meal benefits, was $3.1 \%$. This school, as the rest in the district, used a 90-minute rotating block schedule. There were four periods in a school day and the first period was designated to reading. Physical education classes met in the subsequent three periods. Students, therefore, had physical education on alternating days during the school year. 
All students participated in the same activities throughout the school year. However, the order in which they participated in them varied; students chose their specific activity sequence at the beginning of the school year. Those from the same grade usually had physical education in the same period. The meeting hours for these periods during a particular day varied according to the school's A-day or Bday schedule.

Physical education was taught by one male and two female full-time certified physical education teachers. Their teaching experiences ranged from 10 to 21 years. They were all active American Alliance for Health, Physical Education, Recreation, and Dance (AAHPERD) members. The teachers were arranged to teach selected units in which they had most expertise. Students rotated in taking the units based on their choice of sequence made at the beginning of the school year.

Participants $(N=60)$ were randomly selected from the students enrolled in the required physical education classes. To accommodate research resource limitations (limited number of Digiwalkers and Heart Rate monitors), we randomly selected approximately 10 participants from each of the six physical education periods on A-day and B-day. Due to incomplete data, 3 participants were eliminated from the final data analyses. The final sample consisted of 57 students (19 boys, 38 girls). Included in the sample were 21 sixth-graders, 18 seventh-graders, and 18 eighth-graders. There were 39 (68.5\%) European Americans, 6 (10.5\%) African Americans, 5 (8.5\%) Asian Americans, and 7 (12.5\%) in other ethnic groups. Parental permission was received prior to data collection.

Square dance was chosen as a representation of dance content for the study for two reasons. First, square dance is one of the important activities in the middle school curriculum in the area because of its social and cultural values emphasized in the curriculum. Second, square dance is a physical activity to which students have relatively less exposure outside physical education classes compared with team and individual sports. A survey about student after-school activities was administrated along with the Personal Interest Questionnaire. The result showed that no participants in the study engaged in square dance or other dances outside school. Therefore, the learning outcome measured could be largely attributable to their learning behavior in the lessons. In other words, ecological validity of the findings can be maintained.

The four-week unit was team taught with the male teacher as the lead teacher who had taught the unit for over 10 years. The unit was introduced to the 6thgraders as a new content, taught with the basic knowledge and skills. For the 7 thand 8th-graders, the content was taught in a spirally progressive ways with an emphasis on creativity and cultural understanding. This group of teachers had repeatedly provided training workshops of the dance unit to teachers in the district and the state. The unit was taught with the direct and problem-solving methods and in an alternating four-couple formation focused on rhythm (responses to calls), step (variations), and partner exchange in the formation. Students frequently changed groups to work with different partners. No position was designated in terms of gender.

\section{Variables and Measures}

Situational interest. Situational interest was measured using a 24-item Situational Interest Scale (Chen, Darst, \& Pangrazi, 1999) which was designed to 
measure total situational interest (Total Interest) and its source dimensions (Novelty, Challenge, Attention Demand, Exploration Intention, Instant Enjoyment). The 24 items were randomly placed in the scale and attached with a 5-point Likert type scale $(5=$ strongly agree, $1=$ strongly disagree) for students to rate in terms of the learning tasks they were experiencing.

According to Chen et al. (1999), the construct validity of Situational Interest Scale was established using a factor analytical approach with exploratory and confirmatory factor loadings ranging from 0.50 to 0.90 . The reliability coefficients (Cronbach's $\alpha$ ) were reported to be $.78, .80, .90, .91, .90$, and .95 for Novelty, Challenge, Attention Demand, Exploration Intention, Instant Enjoyment, and Total Interest, respectively. The evidence indicates that Situational Interest Scale can generate valid and reliable data.

Although participants responded to the 24-item scale, the measures of dimensional sources were of little relevance for the purpose of the study. In the analysis, we used the sum (20 points total) of the four Total Interest items to represent the direct measure of situational interest for the purpose of this study. These items included, "What we were learning today looked fun to me," "It was fun for me to try what we were learning," "What we were learning was interesting for me to do," and "What we were learning attracted me to participate."

Personal interest. Personal interest in square dance was examined by asking students to rate square dance along with other 14 activities in the curriculum on a 7 -point Likert-type scale ( $7=$ highest interest, $1=$ lowest interest). At the beginning of the questionnaire the participant was asked to identify an activity (any school or home activity) he/she was most interested in, write it down in a designated place on the questionnaire, rate it 7 , and use it as a reference activity against which the 14 physical activities were compared. This criterion item provided a measurement context in which ratings on the 14 physical activities were based on a criterion activity. According to Tobias (1994), this measurement context can minimize the possibility that individual students exercise their own interpretation of the ratings, thus, better maintain the internal validity of the measure.

Skill/knowledge outcome. Two learning outcome measures were used. One was students' physical intensity level during dance lessons and the other was grades of skill and knowledge assessments. Physical intensity level was measured using Digi-Walker pedometer (Yamax Inc., Model SW-200, Tokyo, Japan) that recorded total steps taken during a lesson. The random error rate for the Digi-Walker pedometers was reported less than $1 \%$ when used to measure moderate physical activities (Bassett, 2000). Selected participants $(N=13)$ were asked to also wear a Polar Heart Rate Monitor (Vantage XL model, Finland) at the same time. The later computed correlation coefficients between the steps and HR data were $.65, .74$, .92 for three separate lessons, suggesting an acceptable concurrent validity of the Digi-Walker pedometer data.

The participants' grades from skill and knowledge assessments were used as the other outcome measure. As a part of the teachers' instructional plan, the assessment included skill tests and knowledge tests. In the dance unit, there were three skill tests (on rhythm, steps, and group coordination) and one written examination. These tests were centered on the content taught in the unit and based on the learning outcome standards in the district's updated curriculum. Students in different grades were assessed in similar skill/knowledge categories (e.g., rhythm, steps, 
knowledge of choreography), but tests for higher grades examined the skill and knowledge at a higher level. For instance, the written test for 6th graders consisted of multiple-choice questions focusing on rhythm, mechanics of steps, etc., while 7 th graders were asked to write essays about those concepts. For the 8th graders, the written test was a research paper on one of several topics, which required them to conduct a library or Internet search for information.

The teachers used a 20-point scoring system in which the points were equally assigned to physical skill and knowledge tests. In order to preserve the authenticity of the learning assessment, we did not impose any additional skill or knowledge assessment. Because the tests were directly derived from the content taught and directly related to square dance, they were deemed having face validity.

\section{Data Collection}

The survey for personal interest and demographic information was conducted in a quiet classroom during the first class period of the unit. The participants were also trained to use the Digiwalker pedometer and Polar Heart Rate (HR) monitor during this time.

Situational interest data and heart rate, Digi-Walker data were collected in three randomly selected instructional lessons (lesson 2, lesson 4, and lesson 10 for each grade level). Before each lesson began, the participants put on and set the Digi-Walker and HR monitor. Immediately after the lesson, they were instructed to stop the HR monitor and record the Digi-Walker data on a recording sheet. The researchers verified this recording with the actual data display on the devices. The participants independently completed the Situational Interest Scale in a quiet room adjacent to the gymnasium. During the data collection, the researchers were responsible for distributing the scales, answering questions, and collecting the completed scales and instruments.

The skill test and written exam scores were collected from the teachers after the unit was complete. Students' written exam and assessment standards were also collected to provide supplemental information about the assessment.

\section{Data Analysis}

All data were subject to a preliminary screening for accuracy and descriptive statistical analysis. Pearson-product moment correlation analysis was conducted to examine relationships among interests and learning outcomes. MANOVA was used to examine the differences between boys and girls in personal and situational interests, Step, and Grade. In the analysis, the aggregated average scores of situational interest and steps from the three lessons were used. Grades were represented using the aggregated standardized average of the teachers' assessment scores for skill and knowledge outcomes.

\section{Results}

Descriptive analysis showed the skewness for all variables ranged from -.80 to .90 , indicating they were distributed normally. The current item consistence reliability coefficients (Cronbach $\alpha$ ) for the 4-item situational interest measure were $.88, .85$, and .82 for the three lessons, respectively. Statistical descriptives of the responses are reported in Table 1. 
Table 1 Descriptive Analysis of Variables by Gender

\begin{tabular}{lcc}
\hline & Male & Female \\
& & \\
& M/SD & M/SD \\
Personal interest & $1.89 / 1.45$ & $3.38 / 1.75$ \\
Situational interest & $14.02 / 2.50$ & $14.98 / 2.81$ \\
Physical intensity (steps) & $1925 / 337$ & $1826 / 352$ \\
Skill/knowledge outcome (grade) & $16.4 / 2.14$ & $18.3 / 1.58$ \\
\hline
\end{tabular}

Note: The maximal score for personal interest $=7$, for situational interest $=20$, for grade $=$ 20.

\section{Correlation Analysis}

Overall, a moderate correlation was found between personal interest and situational interest. A weak but significant correlation was observed between Steps and personal interest. A strong correlation was found between Grade and personal interest. However, there was inconsistency in these correlations between boys and girls. The correlations between situational interest, Steps, and personal interest for boys seem stronger than that for girls while girls have a stronger correlation with Grade than boys.

Situational interests are highly associated with Step for both boys and girls, but situational interest did not associate with Grade for either girls or boys. In addition, Grade was correlated with Step for neither girls nor boys. It seems that there was no direct association between skill/knowledge proficiency and physical intensity level in this dance unit. Table 2 summarizes all correlation coefficients.

\section{Gender Difference in Interests and Outcome}

A MANOVA was used to determine if the boys and girls differed in personal interest and situational interest in dance. The Box $M$ value was $2.52, F(3,31081)=$ $.79, p=.50$, indicating that the equal covariance assumption was not violated. As reported in Table 1, the girls had a statistically significant higher, $F(1,55)=10.20$, $p=.002$, personal interest in square dance than the boys did. The difference between boys and girls on situational interest was not statistically significant, $F$ (1, $55)=1.60, p=.21$. It seems that both boys and girls felt the dance lessons were situationally interesting regardless of their different personal interest in dance.

Because personal interest is often associated with acquired knowledge and skill (Renninger, 2000), it was used as a covariate to control its influence in the subsequent MANOVA analysis on the differences in learning outcomes between the boys and girls. Analyzed results indicated that the boys took more steps during each lesson than did the girls. The girls, however, performed better than boys on skill and writing tests. The differences are statistically significant, $F(1,54)=5.10$, $p=.02$ for Steps; $F(1,54)=5.55, p=.02$ for Grade. 
Table 2 Correlation Coefficients (r) for Interests and Learning Outcomes $(n=57)$

\begin{tabular}{lccc}
\hline & $\begin{array}{c}\text { Situational interest } \\
\text { all/boy/girl }\end{array}$ & $\begin{array}{c}\text { Physical intensity } \\
\text { (Step) all/boy/girl }\end{array}$ & $\begin{array}{c}\text { Achievement } \\
\text { (Grade) all/boy/girl }\end{array}$ \\
\hline $\begin{array}{l}\text { Personal interest } \\
\text { Situational interest }\end{array}$ & $.39 * * / .46 * / .32$ & $.31 * / .60 * * / .32$ & $.57 * * / .26 / .62 * *$ \\
Physical intensity & $.69 * * / .69 * * / .73 * *$ & $.24 / .10 / .23$ \\
& & $-.03 / .13 /-.06$ \\
\hline
\end{tabular}

$* * p<.01 . * p<.05$.

\section{Discussion}

The purpose of this study was to examine the extent to which personal interest, situational interest, and learning outcome differed in boys and girls in a square dance unit. Similar to the results of other studies (Lee et al., 1999), we found that boys' and girls' personal interest in square dance was significantly different. The difference may be an indicator of social influences on students' preference of physical activities and may further reveal students' stereotype toward physical activities. Lee et al. (1999) pointed out that a sense of "gender appropriateness" drives students' competence and motivational beliefs with well-established gender-role conceptions. Boys and girls may not try hard to learn "gender inappropriate" activities. They usually contend that activities "appropriate" to their own gender are more important and deserve their effort. It is suggested (Lee et al., 1999) that physical educators should challenge the traditional, dominant stereotypical views by teaching various types of physical activities in a way that motivates both boys and girls. Students must be convinced that participating in a broad range of cooperative, rhythmic and competitive activities is meaningful and important for both boys and girls.

\section{Functions of Interests}

Based on the analysis, the moderate association between situational interest and personal interest may suggest that to a certain extent, situational interest is associated with personal interest. The finding supports Chen and Darst's observation (2002) that in a highly situationally interesting learning environment, students with high personal interest in the subject may be more cognizant about situational interest and its effect than those with low personal interest. In other words, they view the activity as more interesting and attractive, and rate situational interest higher. In a low situational interest context, this association between personal and situational interest diminishes.

It is worth noting in our data that situational interest motivated both boys and girls in the dance classes, as seen in the positive relationships between Step and Situational interest for both boys and girls. It overcame the influence of gender- 
based personal interest during the learning process, since boys were also highly active despite their lower personal interest. In other words, gender had little impact on the motivational effect of situational interest. Both boys and girls, regardless of their personal interest, experienced high situational interest in the dance lessons. This finding is consistent with Chen and Darst's observation (2001) that gender had limited mediation effect on situational interest.

The higher physical activity intensity level of boys in the dance lessons indicates that the effect of gendered personal interest may diminish when learning tasks possess high situational interest. According to Chen and Darst (2001), situational interest derives from the characteristics in learning tasks such as novelty, cognitive/physical challenge, attention demand, opportunities to explore, and the ultimate positive emotion such as instant enjoyment. In other words, situational interest is always associated with something that can catch students' attention and instantly engage them in learning (Mitchell, 1993). These components are mostly under the teacher's control. The findings suggest that designing situationally interesting learning tasks may overcome students' gendered personal interest toward physical activities in the gymnasium.

The data from this study may lend support for a theoretical learning model proposed by Alexander et al. (1995). In this learning model, learning is assumed to occur following sequential stages of accumulation, competency, and proficiency. Learners at different stages need to be motivated with different type of interests. At the knowledge accumulation stage, when the learner has limited knowledge/ skill, situational interest is the primary motivator for the learner to put forth continuous cognitive effort and energy. At the competency stage, the learner is beginning to master key knowledge and skills. Personal interest should replace situational interest as a major motivator. At this stage, situational interest begins to be internalized into personal interest. At the proficiency stage, the learner becomes proficient in learning. It is likely that personal interest is the sole motivator for further learning.

The low personal interest and high situational interest observed in boys seem to suggest an accumulation learning stage in that the boys were motivated by situational interest in the dance lessons. The high situationally interesting learning tasks overcame the boys' low personal interest in dance. The strong association between situational interest and physical intensity level (Step) indicates that situational interest indeed motivated the boys to actively engage in the learning activities in dance, an activity that is usually considered by them as "gender inappropriate" (Lee et al., 1999).

Research (Chen \& Darst, 2001) has shown that personal interest is strongly associated with acquired knowledge and skills. Girls' better performance in skill and written tests may support the importance of personal interest. Although the girls were not as physically active in class, their learning activity might have higher efficiency and quality than the boys.

It is worthwhile to notice that Grade, reflected in the knowledge and skill assessments, was not associated with situational interest and physical intensity level (Step) for either boys or girls. This result is consistent with Hidi and Anderson's finding (1992) that situational interest may not directly contribute to learning outcome measures. The impact of situational interest on measurable learning outcome may be indirect. 


\section{Physical Intensity and Skill/Knowledge Outcome}

The discrepancy between physical intensity and skill/knowledge outcome (Grade) may indicate some hidden issues in physical education. These issues may include the curriculum incoherence, and seductive detail effect of situational interest.

Issue of curriculum incoherence. Burke (1995) warned that the lack of research on the link between motivation and curriculum has jeopardized successful learning in students. The discrepancy between being active and skill/knowledge outcome may reflect a disconnection between assessment and learning tasks. In other words, the motivated boys and girls either did not learn worthwhile content that was to be assessed, or what was assessed did not require high motivation to strive for in the first place (Ennis, 1998).

In a coherent curriculum students are active for the purpose of learning. They should be taught to acknowledge the importance of the content, actively engage in the learning process, and appreciate learning outcomes, that is, to become more skilled and knowledgeable about physical activity (Ennis et al., 1999). In such a curriculum, students become aware of the connection between their learning effort and outcome, start to value their own motivated participation in learning, and develop strong personal interest in the content. The gap between physical intensity level and skill/knowledge outcome for both boys and girls in our data may suggest that physical educators need to develop a coherent curriculum where motivated learning behavior manifested in measurable physical intensity can be reflected in the skill/knowledge outcome observed in learning assessment.

Effect of seductive detail. Seductive details refer to highly interesting but unimportant content or class activities for the sole purpose of increasing students' attention (Schraw, 1998). Although seductive details can enhance student engagement in the content, they tend to direct students' time, energy, and effort away from important knowledge and skills (Garner, Brown, Sanders, \& Menke, 1992). Research findings in reading and science education indicate that seductive-detailbased interest would have little impact on learning (Wade \& Adams, 1990). In some cases, it may interfere with construction of new knowledge and skill. For instance, in Harp and Mayer's experiment (1997), adding an entertaining story about lightning and a colorful illustration to a scientifically factual text distracted learners cognitive functioning, resulting in a poor knowledge acquisition and retention.

This study was not designed to explore the effects of seductive details in the dance unit. Consequently no data on seductive details were collected. Based on our anecdotal observations, however, we noticed some elements in the classes might function as seductive details. For instance, the teachers often wore various costume dresses instead of their physical education uniforms in teaching the unit. Students' responses to those costume dresses were usually a demonstration of over excitement. The teachers often turned the volume of music high to boost active movement during the lessons. If these elements involved in the lessons distracted the students from working on their steps, turns, rhythms, and group coordination, they became seductive details. It follows that the gap between situational interest, physical intensity and skill/knowledge outcome might reflect the effects of seductive details. Given the descriptive nature of the study, we cannot conclude on the causes of the gap observed. The reader should be aware of the limitation of study and exercise caution when interpreting the findings. 
It seems that further research on seductive details is needed in order for us to better understand situational interest and its effect on learning in physical education. This type of research can provide useful empirical data to inform curriculum designers and teachers in developing strategies to avoid the effect of seductive details while designing a situationally interesting and motivating curriculum.

In summary, in this study we examined the extent to which personal interest, situational interest and measurable learning outcome differed as associated with gender in a middle school square dance unit. Our findings suggest that gender may associate with students' personal interest, but its effect on situational interest was very limited. Since the vast majority of students enrolled in schools can be assumed to have very limited knowledge and value in most school subject matter (Alexander, 2000), we can argue that situational interest is a viable motivator for both boys and girls. Personal interest, however, should be nurtured during the learning process because it is the motivator that leads to persistent effort and achievement in learning (Hidi, 2000). In a motivating learning environment, it is likely that situational interest can be internalized to become student personal interest when students are progressing from accumulative learners to proficient learners (Alexander, 2000). Further research is needed to explore this internalization process in learners in physical education as it is related to various learner characteristics including gender.

Physical education classes are one of the communities of practice that are neither socially neutral nor immune from the influence of the society and social institutions (Gard \& Meyenn, 2000). Repressive gender stereotype and unequal social relations in the wider social community inevitably will find ways to influence school-age learners from early on. The socially constructed "gender appropriateness" in students can mediate their motivation in learning physical activities profoundly. The results of the study have indicated that students' personal interest derived from gender stereotype may be addressed with situational interest. Although it might be beyond the scope of our data, it can be assumed that it is possible to minimize gender stereotype construction in physical education where carefully designed learning tasks may provide a situationally interesting learning environment. In such an environment, students are likely to internalize the content and develop a genuine personal interest in all physical activities.

\section{References}

Alexander, P.A. (2000). Toward a model of academic development: Schooling and the acquisition of knowledge: The sequel. Educational Researcher, 29(2), 28-33, 44.

Alexander, P.A., Jetton, T.L., \& Kulikowich, J.M. (1995). Interrelationship of knowledge, interest, and recall: Assessing a model of domain learning. Journal of Educational Psychology, 87, 559-575.

Anderson, R.C., Shirey, L.L., Wilson, P.T., \& Fieldings, L.G. (1987). Interestingness of children's reading material. In R.E. Snow \& M.J. Farr (Eds.), Aptitude, learning and instruction: III. Conative and affective process analyses (pp. 287-299). Hillsdale, NJ: Erlbaum.

Bassett, D.R. (2000). Validity and reliability issues in objective monitoring of physical activity. Research Quarterly for Exercise and Sport, 71(Suppl. 2), 30-36.

Burke, D.J. (1995). Connecting content and motivation: Education's missing link. Peabody Journal of Education, 70, 66-81. 
Chen, A. (2001). A theoretical conceptualization for motivation research in physical education: An integrated perspective. Quest, 53, 35-58.

Chen, A., \& Darst, P.W. (2001). Situational interest in physical education: A function of learning task design. Research Quarterly for Exercise and Sport, 72, 150-164.

Chen, A., \& Darst, P.W. (2002). Individual and situational interest: The role of gender and skill. Contemporary Educational Psychology, 27, 250-269.

Chen, A., Darst, P.W., \& Pangrazi, R.P. (1999). What constitutes situational interest? Validating a construct in physical education. Measurement in Physical Education and Exercise Science, 3, 157-180.

Clifton, R.T., \& Gill, D.L. (1994). Gender differences in self-confidence on a femininetyped task. Journal of Sport and Exercise Psychology, 16, 150-162.

Crawford, J.R. (1994). Encouraging male participation in dance. Journal of Physical Education, Recreation and Dance, 65, 40-43.

Ennis, C.D. (1998). Shared expectations: Creating a joint vision for urban schools. In J. Brophy (Ed.), Advances in research on teaching (Vol. 7, pp. 151-182). New York: JAI Press.

Ennis, C.D., Solmon, M.A., Satina, B., Loftus, S.J., Mensch, J., \& McCauley, M.T. (1999). Creating a sense of family in urban schools using the "Sport for Peace" curriculum. Research Quarterly for Exercise and Sport, 70, 273-285.

Flintoff, A., \& Scraton, S. (2001). Stepping into active leisure? Young women's perceptions of active lifestyles and their experiences of school physical education. Sport, Education and Society, 6, 5-21.

Gard, M., \& Meyenn, R. (2000). Boys, bodies, pleasure and pain: Interrogating contact sports in schools. Sport, Education and Society, 5, 19-34.

Garner, R., Brown, R., Sanders, S., \& Menke, D. (1992). "Seductive details" and learning from text. In K.A. Renninger, S. Hidi, \& A. Kappa (Eds.), The role of interest in learning and development (pp. 239-254). Hillside, NJ: Erlbaum.

Griffin, P.S. (1985). Teacher's perceptions of and responses to sex equity problems in middle school physical education program. Research Quarterly for Exercise and Sport, 56, 103-110.

Harp, S., \& Mayer, R.E. (1997). The role of interest in learning from scientific text and illustrations: On the distinction between emotional and cognitive interest. Journal of Educational Psychology, 89, 92-102.

Hastie, P.A., \& Pickwell, A. (1996). Take your partners: A description of a student social system in a secondary school dance class. Journal of Teaching in Physical Education, 15, 171-187.

Haussler, P., \& Hoffmann, L. (1998). Qualitative differences in students' interest in physics and the dependence on gender and age. In L. Hoffmann, A. Krapp, K.A. Renninger, \& J. Baumert (Eds.), Interest and learning (pp. 280-289). Kiel, Germany: Institute for Science Education.

Hickey, C., \& Fitzclarence, L. (1999). Educating boys in sport and physical education: Using narrative methods to develop pedagogies of responsibility. Sport, Education and Society, 4, 51-62.

Hidi, S. (2000). An interest researcher's perspective: The effects of extrinsic and extrinsic factors on motivation. In C. Sansone \& J.M. Harackiewicz (Eds.), Intrinsic and extrinsic motivation: The search for optimal motivation and performance (pp. 309339). San Diego, CA: Academic Press.

Hidi, S., \& Anderson, V. (1992). Situational interest and its impact on reading and expository writing. In K.A. Renninger, S. Hidi, \& A. Krapp (Eds.), The role of interest in learning and development (pp. 215-238). Hillsdale, NJ: LEA. 
Krapp, A., Hidi, S., \& Renninger, K.A. (1992). Interest, learning, and development. In K.A. Renninger, S. Hidi, \& A. Krapp (Eds.), The role of interest in learning and development (pp. 1-26). Hillsdale, NJ: LEA.

Lee, A.M. (2002). Promoting quality school physical education: Exploring the root of the problem. Research Quarterly for Exercise and Sport, 73, 118-125.

Lee, A.M., Fredenburg, K., Belcher, D., \& Cleveland, N. (1999). Gender differences in children's conceptions of competence and motivation in physical education. Sport, Education and Society, 4, 161-175.

Mitchell, M. (1993). Situational interest: Its multifaceted structure in the secondary school mathematics classroom. Journal of Educational Psychology, 85, 424-436.

National Association for Sport and Physical Education. (1995). Moving into the future: National standards for physical education. A guide to content and assessment. St. Louis, MO: Mosby.

Pintrich, P.R., \& Schunk, D.H. (2002). Motivation in education: Theory, research and applications (2nd ed.). Englewood Cliffs, NJ: Prentice-Hall.

Reeve, J. (1996). Motivating others: Nurturing inner motivational resources. Needham Heights, MA: Allyn \& Bacon.

Renninger, K.A. (2000). Individual interest and its implications for understanding intrinsic motivation. In C. Sansone \& J. M. Harackiewicz (Eds.), Intrinsic and extrinsic motivation: The search for optimal motivation and performance (pp. 373-404). San Diego, CA: Academic Press.

Schraw, G. (1998). Processing and recall differences among seductive details. Journal of Educational Psychology, 90, 3-12.

Tobias, S. (1994). Interest, prior knowledge, and learning. Review of Educational Research, 64, 37-54.

Wade, S.E., \& Adams, R.B. (1990). Effects of importance and interest on recall of biographical text. Journal of Reading Behavior, 12, 331-353.

Williams, A., \& Bedward, J. (2001). Gender, culture and the generation gap: Student and teacher perceptions of aspects of National Curriculum Physical Education. Sport, Education and Society, 6, 53-66.

Williamson, K.M. (1996). Gender issues. In S.J. Silverman \& C.D. Ennis (Eds.), Student learning in physical education: Applying research to enhance instruction (pp. 81100). Champaign, IL: Human Kinetics. 